\title{
La institucionalización de utopías izquierdistas en América Latina: un estudio de caso
}

\author{
Institutionalization of leftist utopias in Latin America: \\ a case study
}

Guillem Compte Nunes ${ }^{1}$

Fecha de recepción: 8 de febrero de 2021

Fecha de aceptación: 11 de marzo de 2021 


\section{Resumen}

Ante la insatisfacción popular con la democracia liberal-capitalista, a principios del siglo XXI se produce un giro gubernamental a la izquierda en América Latina, del cual participa recientemente México, con la llegada del partido Morena al poder. Los movimientos sociales que impulsan estos proyectos políticos vehiculan utopías de cuño izquierdista que pretenden institucionalizarse en los sistemas políticos y las políticas públicas. Sin embargo, este proceso de institucionalización utópica presenta tensiones y contradicciones adentro de los denominados partidos-movimiento. En este trabajo presento una propuesta metodológica para el análisis utópico, que aplico al "Colectivo La Calle", grupo integrante del movimiento lopezobradorista en México. Analizo tres utopías mediadas por este grupo y encuentro que efectivamente el Colectivo se moviliza contra el pragmatismo de Morena. Este resultado se suma a la literatura previa, que, con motivo de las experiencias gubernamentales contemporáneas, cuestiona la habilidad de la izquierda institucional latinoamericana para superar la hegemonía conservadora.

Palabras clave: utopía, lopezobradorismo, México, acción colectiva, Morena.

\section{Abstract}

Faced with popular dissatisfaction with liberal-capitalist democracy, at the beginning of the 21st century, there is a governmental shift to the left in Latin America, in which Mexico is recently participating, with the arrival of the Morena party to power. The social movements that promote these political projects convey leftist utopias that seek to institutionalize themselves in political systems and public policies. However, this process of utopian institutionalization presents tensions and contradictions within the so-called party-movements. In this paper, I present a methodological proposal for utopian analysis, which I apply to the "Colectivo La Calle", a group that is part of the lopezobradorista movement in Mexico. I analyze three utopias mediated by this group and find that indeed the Colectivo is mobilizing against Morena's pragmatism. This result adds to previous literature, which, given contemporary governmental experiences, questions the ability of the Latin American institutional left to overcome conservative hegemony.

Keywords: utopia, lopezobradorismo, Mexico, collective action, Morena. 


\section{Introducción}

$\mathrm{E}$ 1 diálogo entre la serpiente y Eva en el Paraíso ilustra de forma mitológica cómo política y utopía se imbrican en el devenir humano. El orden social establecido (el Paraíso) puede ser reimaginado y convertirse en objeto de deseo colectivo ("seréis como dioses", dice la serpiente), motivando la contienda política en pos del cambio estructural, paradigmático.

La utopía se presenta como solución radical y total que promete, figurativamente, el regreso al Edén. Pese al fracaso histórico de la utopía comunista, ésta sigue alimentando la disputa por el poder y su ejercicio, debido a la persistente desigualdad social. Así, en los tres primeros lustros del siglo XXI la mayoría de países latinoamericanos amparan gobiernos que movilizan utopías izquierdistas, atentas a la igualdad socioeconómica. Sin embargo, el subsiguiente retroceso de esta denominada 'marea rosa' (Emerson, 2018) en favor del conservadurismo plantea dudas sobre la capacidad de implantación del ideario progresista (Zibechi, 2016; Fair, 2017). De ahí que sea de interés investigar la manera en que se tensionan las utopías cuando sus mediaciones alcanzan el poder político y pretenden institucionalizarlas.

Este giro a la izquierda llega finalmente a México con la victoria presidencial de Andrés Manuel López Obrador (AMLO) en 2018. Como otros líderes políticos carismáticos, AMLO configura un movimiento popular, el lopezobradorismo, que vehicula su acceso al poder (Bolívar, 2014). En el presente trabajo indago la interacción entre utopías que articulan este movimiento social (MS) y su principal derivada institucional, el partido Morena. Específicamente, examino la relación entre ideología e institucionalización utópicas. Para abordar esta cuestión, y dado el escaso desarrollo metodológico en el estudio empírico de las utopías mediadas por MS (Compte, 2020), propongo, en primer lugar, una metodología que denomino análisis narrativo del campo utópico (sección Metodología). Un segundo objetivo es aplicar este enfoque a una mediación utópica lopezobradorista y contrastar una hipótesis procedente de la literatura sobre nuevos partidos políticos (Resultados). Tercero, vinculo los hallazgos a la discusión sobre la instauración contemporánea de utopías izquierdistas en América Latina (Discusión).

\section{Marco teórico}

Partiendo de Ruth Levitas (2010), defino utopía como un deseo colectivo totalizante que transita de un presente criticable a una transformación a futuro. Por tanto, implica una doble totalización: a nivel sincrónico, de un conjunto de discontinuidades entre lo criticado y lo deseado; $y$, a nivel diacrónico, una totalización en toda la temporalidad. Totalizar significa reificar o tratar una construcción social como algo absoluto, necesario y deseable, por encima de la voluntad humana.

Como advierte Karl Mannheim (2004, pp. 242-248), cada época histórica se estructura (en parte) por medio del campo utópico, o sea, el conjunto de procesos utópicos que coexisten y compiten para imponerse como fundamento verdadero de la realidad -el deber-ser que trasciende y dimensiona la experiencia vital. Entendiendo que la distinción utopía versus ideología de este autor es en el fondo arbitraria (Levitas, 2010, pp. 87-91), dicho campo incluye no sólo las utopías contrahegemónicas, que se orientan al cambio de statu quo, sino también las 'ideologías' dominantes, o utopías hegemónicas, que 
procuran el perfeccionamiento del orden social. Estos procesos utópicos toman cuerpo en mediaciones sociales, dotándolas de aspiraciones y proyectos políticos; a su vez, el comportamiento mediacional refleja la incorporación utópica y canaliza el desarrollo histórico de las utopías.

El desencanto con la utopía comunista motiva dilucidar un principio central de la teoría del cambio social, la dialéctica entre lo instituyente y lo instituido (Carretero, 2008). Lo instituyente entraña la fuente inagotable de creatividad social que continuamente abre la experiencia humana al cambio, mientras que lo instituido viabiliza, pero a la vez limita, esa capacidad generativa en instituciones que estabilizan la convivencia. El impulso instituyente exige desbordar lo ya instituido e instituirse en 'mejores' formas; por su parte, la realidad instituida procura perpetuarse en aras del mantenimiento del orden social, intentando evitar el 'caos' de la desestructuración instituyente. De este modo, se establece un círculo dialéctico de negación y superación entre ambos momentos. Este principio proporciona una primera aproximación a la comprensión de la institucionalización utópica: la utopía busca instituirse, pero, en la medida en que pasa del momento instituyente al instituido, pierde potencial transformador al negociar su acomodo en y con lo previamente existente.

La literatura sobre Morena se ha centrado en el liderazgo carismático de AMLO, la victoria electoral de 2018 y la estrategia comunicativa, sin abordar la pugna entre facciones morenistas, ni las tensiones entre la dimensión utópica-ideológica y la estatal-institucional; esto quizá porque en la meteórica ascensión del partido -cuatro años de fundarse a gobernar el país- se ha priorizado la (imagen de) unidad partidaria en torno a la figura del caudillo. No obstante, Rosendo Bolívar, que ha estudiado a Morena desde su fundación en 2014, observa un proceso de oligarquización interna:

Los liderazgos reales y formales se convierten en cuerpos burocráticos que centralizan la autoridad y la toma de decisiones, teniendo la habilidad de evitar la disidencia y la oposición interna, ofreciendo incentivos, negociando con ésta y/o cooptándola, para que desaparezca. No hay facciones ni corrientes o grupos en su interior que vulneren la soberanía de la organización y el poder se encuentra centralizado en la figura carismática de López Obrador. (2017, p. 486)

Aquí veremos cómo esta aparente unidad se resquebraja en la confrontación entre la base lopezobradorista y la élite morenista por el alma del autodenominado partido-movimiento.

Estudios del partido político español Podemos aportan pistas adicionales sobre la institucionalización utópica. Este partido, con vida paralela a Morena, surge en 2014 tras el MS llamado 15M como respuesta de un sector activista a la impermeabilidad del sistema político a sus demandas (Calvo y Álvarez, 2015, p. 116; Díaz et al., 2017, pp. 357-358). El utopismo del 15M se encauza en un proyecto político-electoral y ello da pie a comparaciones entre la matriz contestataria original y su supuesto heredero político (Feixa et al., 2015). Al respecto, Cristina Flesher (2007) propone años antes una distinción tipológica entre movimientos autónomos e izquierda institucional que adquiere relevancia en la conceptualización de la relación entre 15M y Podemos (citado en Calvo y Álvarez, 2015, p. 117). Los movimientos autónomos, como el 15M, abogan por una 'nueva política' que se opone a las prácticas tradicionales de la partidocracia, enfatizando el asamblearismo, la fragmentación de liderazgos, el trabajo en redes horizontales y descentralizadas, la democracia radical y el anticapitalismo. Aunque en su discurso la izquierda institucional, como Podemos, se adhiere a esta nueva política, sus prácticas se alinean, más bien, con los 'viejos’ 
partidos, en sintonía con la lógica de la lucha política institucional (de Nieves, 2015). Justo en la asamblea fundacional de este partido se enfrentan las corrientes autónoma e institucional, ganando la segunda, liderada por Pablo Iglesias. "Estas dos visiones encontradas han seguido presentes tanto en el seno de algunos círculos [estructura base de Podemos], como de los mismos órganos ejecutivos, como desde voces externas al partido más cercanas al 15-M" (Martín, 2015, p. 109). En esta línea, el discurso anticorrupción, de fácil rentabilidad electoral, ha tomado precedencia sobre el cuestionamiento económico $\mathrm{u}$ otros asuntos controvertidos que puedan restar votos (Calvo y Álvarez, 2015, p. 120; de Nieves, 2015, p. 26; Díaz et al., 2017, p. 362). En suma, la institucionalización política del 15M en Podemos comporta un pragmatismo político-institucional que diluye su carácter utópico, lo cual concuerda con el principio dialéctico instituyente-instituido y la oligarquización de Morena apuntada por Bolívar (con base en la llamada ley de hierro de la oligarquía partidaria de Robert Michels). Estas consideraciones conducen a la hipótesis general de discordia interna en movimientos que incluyan mediaciones utópicas instituyentes y proyectos partidarios que pretendan instituir las utopías mediadas.

Para conceptualizar la relación adentro de un MS orientado a la política institucional, como el lopezobradorismo, entre grupos de corte utópico-instituyente y aquellos de orientación institucional se puede recurrir a la teorización de movimiento y contramovimiento social (CMS), sólo que ampliándola al esquema de inteligibilidad dialéctico (Berthelot, 1998, citado en Castellanos, 2013) y a un enfoque procesual (Emirbayer, 1997). Ello se justifica, al menos de forma preliminar, atendiendo a la hipótesis de oposición entre ambos bandos en el plano utópico. El partido político, que domina la conducción del MS, busca traducir la(s) utopía(s) instituyente(s) en estrategias, programas y políticas, mientras que grupos utópicos a su interior desplegarían rasgos de CMS, en oposición a la dilución utópica.

El estudio de la relación MS-CMS surge en el marco de la teoría de la movilización de recursos (TMR), fundamentada en la tesis de que los MS racionalizan la realidad, desplegando medios contestatarios para alcanzar determinados fines. Según McCarthy y Zald (1977, pp. 1217-1218), "a countermovement is a set of opinions and beliefs in a population opposed to a social movement". En otro trabajo seminal Zald (1979, p. 5) caracteriza la dinámica MS-CMS como guerra, metáfora que fundamentará la subsecuente teorización del fenómeno como una retroalimentación y coevolución hostil entre MS y CMS (Meyer y Staggenborg, 1996). Así, gran parte de los casos estudiados implican 'guerras culturales' entre MS progresistas y CMS conservadores, particularmente en Estados Unidos (p. ej. Dorf y Tarrow, 2014). En nuestro caso, el MS asume un tinte conservador, institucionalista, y el CMS intenta mantener el progresismo instituyente original. Según la TMR, estos contrincantes movilizan recursos (oportunidades políticas, ideología, recursos organizacionales, etc.) para lograr su cometido y vencer al enemigo. Sin embargo, esta teoría ha sido criticada por asumir demasiada racionalidad. Ni las personas ni los grupos priorizan siempre criterios racionales, aparte de que frecuentemente no está claro qué es lo racional (Estrada, 2015, pp. 103-112). Además, la idea de recursos como cosas que se utilizan a voluntad oculta que los actores sociales, aunque no lo adviertan, son producto de esas 'cosas'. Por ejemplo, ¿qué tanto un colectivo posee una ideología o, más bien, es poseído por ella? ¿La ideología es racional o, quizá, la racionalidad es ideológica?

Estas dificultades empiezan a resolverse con la teoría de los nuevos movimientos sociales, que reconoce el papel preponderante de la dimensión simbólica de la realidad, por encima de la racionalidad. Aunque esta teoría, como la TMR, asume el protagonismo de personas y colectivos como actores sociales, considera que son producto de una confluencia de procesos que cruzan la sociedad, 
conformando identidades y comportamientos (Melucci, 1991). Dado que el MS surge de la matriz social preexistente, constituye una apropiación parcial de esa totalidad y se puede indagar qué procesos configuran esa mediación. Esto da pie a distinguir analíticamente las mediaciones de los procesos que las conforman. Separar proceso y mediación en el análisis de un MS implica dos ajustes. Por un lado, no se puede asumir a priori que cada grupo de un MS (GMS) se apropie de la misma manera de los procesos que lo configuran. Esto relativiza el valor analítico del concepto MS y lo relega a una concepción identitaria de los nativos. Por otro lado, qué constituyen procesos relevantes depende del MS y el tipo de investigación. Por sus características, el proceso utópico favorece mediaciones que se orientan a voluntarismo, incentivos intangibles y ambiciosas pretensiones de cambio social.

\section{Metodología}

El estudio empírico de las utopías y sus mediaciones está escasamente desarrollado. En otro lugar se ha delineado una propuesta teórico-metodológica que aplica la teoría de los marcos de la acción colectiva a la utopía (Compte, 2020). Aquí planteo un método alternativo, que puede denominarse análisis narrativo del campo utópico. Tras realizar una descripción general de este enfoque, considero la selección del caso, la recogida de datos y el procedimiento de análisis.

\subsection{Descripción}

El análisis narrativo del campo utópico básicamente consiste en comparar el discurso de las mediaciones utópicas con los relatos maestros de las utopías que articulan tales mediaciones. Un relato maestro es una narración o historia que sintetiza la comprensión del mundo según cierta utopía. Estos relatos (que también fundamentan ideologías, mitos y religiosidades) orientan no sólo el discurso sino también las prácticas sociales (Polletta et al., 2011). Por ejemplo, para Podemos José Luis Dader (2015, p. 32) sugiere el siguiente relato mítico:

Un grupo de jóvenes valientes y honestos, henchidos de una rabia justiciera y necesaria, guiados por el más brillante y clarividente de sus miembros, llegó al centro de la política española para desterrar de forma implacable a todos los corruptos e instaurar desde la supremacía moral de sus propuestas solidarias una nueva práctica política de participación popular y prosperidad generalizadas....

Sin embargo, esto asume una convergencia entre utopía y mediación que ignora la complejidad e historicidad del campo utópico. En realidad, la configuración de utopías propias de (G)MS deriva de dicho campo; es decir, este relato maestro de Podemos se nutre de utopías preexistentes que se imbrican y reconstruyen en el partido.

El análisis narrativo forma parte de una estrategia analítica más amplia -análisis del campo utópico- que implica dos tareas. Por un lado, supone determinar la matriz utópica-mediacional, que cruza el campo con las mediaciones de interés investigativo. Para ello es necesario tomar en cuenta el contexto 
sociopolítico en el que se mueven las utopías y surgen los MS, tanto a nivel coyuntural como en un marco histórico de mayor alcance. Asimismo, deben considerarse las evidencias empíricas de encarnación utópica, en otras palabras, las prácticas colectivas (incluyendo prácticas discursivas) que indican la operación de una o varias formas de deseo totalizante. Ahora bien, no se trata de elaborar una matriz exhaustiva; este instrumento analítico debe integrar las utopías y mediaciones pertinentes para abordar objetivos de investigación concretos. Luego, la segunda tarea de análisis supone examinar las interacciones matriciales a nivel sincrónico y/o diacrónico, es decir, cómo los grupos adentro y/o afuera de un MS se interrelacionan en el marco de los procesos utópicos. Ello debe poner de relieve: (i) las similitudes y diferencias en la manera en que los procesos utópicos son incorporados por las mediaciones; (ii) las atribuciones utópicas de los grupos respecto a sí mismos y en relación con otras mediaciones de interés; y (iii) los conflictos mediacionales en clave utópica. Dentro de esta estrategia, el análisis narrativo se enfoca a contrastar los relatos maestros con el discurso de las mediaciones seleccionadas.

En la recogida de datos discursivos el investigador/a puede poner de relieve el proceso utópico observando y registrando la respuesta mediacional a sucesos 'detonadores' de la movilización de las utopías incorporadas. Se trata de eventos internos o externos a un (G)MS que abiertamente desafían o contradicen un relato maestro. En cuanto al procedimiento de análisis, puede emplearse toda la variedad de técnicas propias del análisis del discurso.

\subsection{Selección del caso}

Ilustraré la aplicación de este método al "Colectivo La Calle" (CLC), una mediación utópica adentro del lopezobradorismo en la Ciudad de México. El CLC se identifica con el movimiento del presidente, pero a la vez se posiciona como CMS respecto a la "burocratización" del lopezobradorismo vía Morena: "si en Morena hay movimiento pues vamos a ser de ese movimiento, pero si Morena vemos que se burocratiza, pues entonces le vamos a ayudar desde el movimiento a sacudirse" (Villanueva, reunión de 1 feb. 2020).

Los criterios de selección fueron de acceso y perfil. El CLC está abierto a la participación de toda la ciudadanía, no sólo de quienes se consideran lopezobradoristas; y, además, acogió sin reservas (en una reunión) mi deseo de estudiarlo. El perfil utópico del CLC comprende, por un lado, su voluntarismo y activismo social, un discurso que remite a valores últimos (justicia, igualdad...) y la fijación grupal en la "transformación" de México de la mano del gobierno de AMLO; por otro lado, implica una disociación respecto al partido Morena y los incentivos tangibles de la militancia partidaria.

\subsection{Recogida de datos y procedimiento de análisis}

Los datos derivan de un acompañamiento etnográfico al grupo entre agosto de 2019 y abril de 2020, e incluyen los registros de observaciones participantes de reuniones y otras actividades, la publicación La Calle, una entrevista con el líder y un documental del CLC sobre sí mismo. El análisis de estos datos discursivos se centra en su dimensión semántica. Aprovecho dos sucesos detonadores para evidenciar la movilización utópica y el posicionamiento contrapuesto del grupo respecto a Morena. 


\section{Resultados}

\section{1. "Colectivo La Calle" y eventos detonadores}

El CLC es un grupo político orientado al espacio público local -de ahí su nombre-, concretamente la alcaldía de Coyoacán de la Ciudad de México. Se origina en septiembre de 2016 a iniciativa de su "coordinador", Gerardo Villanueva, a raíz de una protesta contra la privatización de una antigua planta de asfalto. Cuando Morena critica la movilización porque ésta usa el nombre del partido "entonces nosotros dijimos, caray, Morena no ha hecho una sola asamblea con la población en un año... y nos están reclamando, ¿en serio?, entonces, perfecto, hagamos un brazo social” (G. Villanueva, comunicación personal, 11 de febrero de 2020). Así, no es requisito militar para participar en el grupo, aunque éste se declara lopezobradorista y la mayoría de integrantes están afiliados al partido.

El CLC se autodescribe como "colectivo de colectivos", porque incluye activistas que a su vez pertenecen a otros grupos, lo cual incrementa su incidencia sociopolítica. La participación es voluntaria y sin pago de cuota. Los tres pilares de labor son la reunión periódica, la publicación del periódico $L a$ Calle y otras actividades de organización social, incluyendo eventos culturales, iniciativas político-institucionales, movilización partidista, acciones de protesta, y difusión en redes sociales. Las reuniones, semanales o bimensuales y convocadas vía WhatsApp y Facebook, se llevan a cabo los sábados en el mismo lugar, de 18:30 a 20:30 aproximadamente. Cuentan con una asistencia promedio de 50 personas, la mayoría mujeres y hombres de más de 50 años. Estos encuentros vertebran las demás actividades. Inician y terminan con una introducción y un cierre por parte de Villanueva, en los que coordina al grupo y comenta la realidad política; en medio, se realiza una charla política o un taller por parte de ponentes invitados. En cuanto al periódico, es una publicación mensual gratuita, de 10 a 30 páginas, con la misión de "escribir como pueblo y hacer leer al pueblo" (CLC, 2019a, p. 5). Informa a la ciudadanía de asuntos de interés público, promueve la ideología lopezobradorista y vincula el grupo a la comunidad local (p. ej. propiciando reclutamiento). Lo elaboran el coordinador y otras tres personas, con colaboraciones puntuales de integrantes del CLC o articulistas invitados. Cuando un número está listo se reparten copias en la reunión y se forman "brigadas", pequeños grupos que caminan las calles de distintas vecindades, regalando la publicación, aunque recientemente se ha favorecido su distribución digital. Desde el inicio del CLC hasta abril de 2020 se han publicado 43 números.

Destaco dos eventos que, como agujas de acupuntura, activan la circulación utópica en el grupo, disparando filias y fobias en relación con la dirigencia de Morena. El primero enfrenta a dos senadores morenistas, Martí Batres y Ricardo Monreal, por la presidencia del Senado. En agosto de 2019 el primero quiere reelegirse, pero el segundo maniobra para encumbrar a otra candidata. Aunque Morena invalida la elección, Batres renuncia a reeditarla, afirmando que no hay condiciones de imparcialidad (Infobae, 2019). En esas fechas asisto por primera vez a la reunión del CLC y presencio una explosión de indignación; ahí aprendo que el coordinador es colaborador cercano de Batres. El segundo evento implica la sucesión a AMLO en la presidencia del partido, que en principio debe llevarse a cabo en noviembre de 2019, tras un proceso asambleario de la militancia. Sin embargo, Yeidckol Polevnsky, presidenta en funciones, y otros dos aspirantes, Alejandro Rojas y Mario Delgado, se oponen al proceso; esto a diferencia 
de Bertha Luján, la cuarta candidata. Finalmente, el Tribunal Electoral del Poder Judicial de la Federación anula la elección, argumentando irregularidades en la conformación del padrón electoral. Como respuesta, el Comité Ejecutivo Nacional, liderado por Luján, convoca a un Congreso el 26 de enero de 2020, en el que se elige a un presidente interino, desplazando a Polevnsky. Un mes después el Tribunal valida este encuentro, pero ordena la realización de una encuesta a población abierta para determinar la presidencia y la secretaría general de Morena, lo cual genera el repudio de Luján y la satisfacción de los otros tres candidatos. A la espera de la encuesta, un sondeo sitúa a Delgado como la persona que "tiene mayor experiencia para conducir a Morena al triunfo electoral”, por delante de Rojas y Polevnsky, con Luján en último lugar (Heraldo, 2020). En esta pugna el CLC ha apoyado a Luján, quien en 2015 fue candidata a la alcaldía de Coyoacán.

\subsection{Matriz utópica-mediacional}

La matriz comprende dos ejes, las mediaciones utópicas y las utopías relevantes (Cuadro 1). El primero incluye los dos GMS de interés para el problema de investigación planteado, el CLC y Morena; el segundo, tres utopías pertinentes al contexto histórico-político mexicano y la coyuntura política de alternancia presidencial en 2018. La selección de estas tres utopías constituye un recorte analítico, sin afán de exhaustividad. A continuación, presento el análisis por utopía, mostrando las tensiones entre grupo utópico y partido, particularmente a la luz de los dos sucesos detonadores.

\begin{tabular}{|c|c|c|c|}
\hline & \multicolumn{2}{|c|}{$\begin{array}{c}\text { Cuadro 1 } \\
\text { Parámetros, Descripción y Medición }\end{array}$} & \\
\hline & & \multicolumn{2}{|l|}{ MEDIACIONES } \\
\hline & & \multicolumn{2}{|l|}{ MS: lopezobradorismo } \\
\hline & & $\begin{array}{l}\text { GMS no dominante, } \\
\text { conceptualizado como CMS: } \\
\text { CLC }\end{array}$ & GMS dominante: Morena \\
\hline \multirow{3}{*}{ UTOPÍAS } & Heroísmo salvífico & & \\
\hline & Poder popular de izquierda & & \\
\hline & Posneoliberalismo & & \\
\hline
\end{tabular}

Elaboración propia / Matriz utópica-mediacional para investigar la hipotética confrontación utópica entre el CLC y Morena.

\subsection{Heroísmo salvífico}

La utopía del heroísmo salvífico despliega una hermenéutica centrada en la trama de un personaje, el héroe salvador, que, enfrentándose a agentes del Mal, se sacrifica por su comunidad, salvándola de la perdición y conduciéndola al pleno goce del Bien. El cristianismo constituye la expresión más potente de esta utopía en Occidente en los dos últimos milenios y en América el mesianismo político de inspiración cristiana tiene amplio arraigo (Alexander, 2009; Pinho, 2020). En esta línea, el CLC declara tener como motivación y objetivo principal el cambiar el mundo a mejor: "tenemos la misión de 
vivir en un lugar mejor, y buscar vivir en un lugar mejor es buscar transformar el mundo" (Villanueva, reunión 7 sep. 2019). Se desea un cambio sustantivo y duradero; por ello el CLC, siguiendo el discurso lopezobradorista, emplea "transformar" para construir discursivamente la metamorfosis social que este MS estaría efectuando. Por mundo se entiende México y, en particular, las colonias de Coyoacán donde residen la mayoría de participantes. Asimismo, la experiencia heroica integra facetas individual y colectiva: cada miembro puede sentirse salvador del mundo y, a la vez, el CLC se identifica con el colectivo protagónico de la Historia mexicana, "el pueblo", que "tiene sus intereses, que es la liberación como su principal meta" (Villanueva, reunión 30 nov. 2019). Esta afirmación recuerda a la teología de la liberación, corriente latinoamericana que combina cristianismo y marxismo. De hecho, Villanueva (comunicación personal, 11 de febrero de 2020) relata que su primer "círculo de estudio" en 1997 práctica que dos décadas después inspira las reuniones del CLC- aborda esa teología.

Tres rasgos marcan este heroísmo salvífico: altruismo, trabajo y moral. Los participantes se creen completamente dedicados a la causa transformadora. Esta autopercepción se apoya en la desvinculación organizacional del CLC respecto a Morena; el Colectivo reúne a afiliados del partido, pero presumiblemente bajo otra lógica: "aquí nos hemos encontrado en un punto con mayor confianza, donde no estamos alegando porque no me tocó X cosa, sino porque queremos que a México le toque un futuro" (Villanueva, reunión 7 sep. 2019). El CLC representa, según otro testimonio, "un dar sin esperar recibir nada" (CLC, 2019b). El trasfondo cristiano de tal desinterés se asoma en alusiones a la sacrificada membresía caracterizándola como "riqueza” y "tesoro" (CLC, 2019a, p. 6), o a "nuestro reino político", que "es más grande que lo que puedan tener de huesillos [= cargos públicos] los [oportunistas] que llegaron a buen momento... porque también gracias a ellos tenemos a Andrés Manuel como presidente" (Villanueva, reunión 31 ago. 2019). Así, incluso quienes parecen entorpecer el cambio en realidad contribuyen al advenimiento de la Providencia política. Por otro lado, en lugar de recurrir a lo sobrenatural, el altruismo se justifica apelando a la Nación, o sea, se imbrica con la utopía nacionalista. Se conjura la imagen de una Nación 'virgen' -inocente, pura, buena- que ha sido violentada por una élite rapaz, cuya estirpe inicia con los conquistadores españoles y se reproduce hasta el gobierno saliente en 2018: "nuestros ancestros practicaron y crearon un estatus vivencial en la nobleza lejos de influencias nocivas y enfermas de ideas y pensamientos obsoletos... Desde que llegaron algunos extranjeros a nuestras tierras, con la falsa idea de conocer nuevos mundos, prevaleció la injusticia" (Martínez, 2019). Este planteamiento conlleva una oposición moral a la racionalidad instrumental, concretamente a las 'grillas' experimentadas en la militancia partidaria: "lo que me ha decepcionado de Morena... [es] todos a buscar, a ver qué agarramos -hueso. Yo nunca vine a buscar hueso, yo vine porque quiero un México mejor para mis nietos" (participante, reunión 7 sep. 2019). De esta manera, el CLC actúa como CMS al lopezobradorismo oficialista, de partido, que distribuye "huesos" en la política institucional.

En segundo lugar, el heroísmo se revela como sacrificio o altruismo laborioso, lo cual implica "lucha" y meritocracia. La lucha exige enfrentar y vencer adversidades, incluso persecuciones: "las [situaciones] que pasamos juntos... nos amenazaron... a ustedes varios los golpearon" (Villanueva, reunión 24 ago. 2019). Requiere constancia, que es recompensada porque luchando se trasciende la cotidianidad egoísta y se experimenta la dimensión solidaria e 'histórica' de la Humanidad. El coordinador enseña el "materialismo dialéctico", es decir, "las reglas de la Historia... el choque de contrarios para generar eventos evolutivos" (reunión 7 sep. 2019). Además, la verdadera amistad se fundamenta en la lucha: "nos hacemos amigos en las brigadas -eso es lo bonito-, no en los cafés. Lo chingón de La 
Calle... es que no nos hacemos amigos en cuestiones sociales, sino en la lucha" (reunión 1 feb. 2020). Por eso un participante indica que "el Colectivo representa una extensión de mi familia" (CLC, 2019b). Lo contrario, reprobado por el CLC, es "lo cómodo", ya sea por indiferencia a la política o "seguidismo" a caudillos, AMLO incluido (Villanueva, reunión 7 sep. 2019). El Colectivo incorpora, por tanto, un lopezobradorismo que relativiza a su líder -segundo elemento contramovilizador-, apostando por una generalización de la participación política, o sea, una politización de la cultura política. Esto incluye priorizar la meritocracia -correlación entre poder y logros previos- por encima del amiguismo, como indica este participante: "deben de llegar [a los cargos del partido] aquellos que realmente han trabajado y han demostrado que están con la institución; a eso le llamo institucionalidad... [porque] si esas personas no tienen el perfil -les vale-, Morena se va a caer" (reunión 7 sep. 2019).

El tercer rasgo heroico, la integridad moral, enfatiza el cultivo de valores humanos a nivel práctico y formativo: "lo que se pretende con la educación moral de la 4T es formar hombres de buen corazón e inclinarlos al bien. Tarea invaluable en una sociedad [,] con ella se ganará la batalla [de valores, la] más importante que se tiene en este gobierno en todos los ámbitos" (Sandoval, 2020, p. 6). Villanueva advierte que esta "batalla" se conduce desde el enojo, afecto agónico que "te levanta, te hace mirar la injusticia, te hace reaccionar humanamente para darle la mano al prójimo... es una conducta ética" (reunión 31 ago. 2019). Aquí influye el lopezobradorismo, que ha capitalizado el hartazgo popular con la corrupción y predica la regeneración moral del tejido sociopolítico. Esta autoimagen moralizante conduce a un sentimiento de superioridad, pero no respecto a la sociedad sino al partido, lo cual constituye otro posicionamiento contramovilizador: "los 'recién llegados' [a Morena]... son bienvenidos en tanto ajusten su comportamiento a nuestra normativa interna y muestren el debido respeto a la lucha que dio como resultado la creación de Morena" (Sánchez, 2019, p. 4). Surge, además, la pretensión de dar ejemplo: "queremos inspirar a otros colectivos, organizaciones políticas y asociaciones civiles para que hagan algo parecido a lo que hacemos" (CLC, 2019a, p. 5).

En la línea de modelar la utopía salvífica, el CLC entroniza y demoniza a ciertos héroes y antihéroes. El episodio del Senado propicia un par de reuniones dedicadas a apoyar a Batres y rechazar a Monreal de forma contundente. De un lado, Batres sería un político cabal, con una larga trayectoria de izquierda, comprometido con las causas del pueblo, que ha hecho una excelente labor en el Senado: Batres es "de los pocos de la verdadera izquierda... que están ahorita en el gobierno. ...yo le conozco desde el 97; es una persona sensible, es una persona honesta, es una buena persona... y así se ha mantenido hasta la fecha" (participante, reunión 24 ago. 2019). Igualmente, en la pugna por el control del partido Luján comanda la lealtad del CLC: el coordinador le dedica una editorial cuasipanegírica en La Calle (Villanueva, 2019); otro integrante atestigua que la dirigente "tiene los ideales de Morena de no mentir, no robar, no traicionar, porque ese es el propósito del partido" (reunión 24 ago. 2019). Del otro lado, Monreal y los contrincantes de Luján personifican la manipulación del partido para ambiciones particulares, sin altruismo ni méritos ni moral. Representan una categoría de militantes indeseables, descritos como "trepadores", "oportunistas" y "arribistas": "no hay un Monreal, hay muchos monreales... que quieren apoderarse de lo que Morena consiguió" (participante, reunión 24 ago. 2019). Estos enemigos internos al lopezobradorismo son lobos con piel de cordero que amenazan la viabilidad de la "transformación", mucho más que la oposición de otros partidos, cosa ajena a las preocupaciones del Colectivo. De este modo, el CLC enfrenta la corriente lopezobradorista capitaneada por estos antihéroes y establece una discontinuidad irreconciliable entre militantes auténticos y espurios. 


\subsection{Poder popular de izquierda}

Esta utopía supone grosso modo la colectivización del heroísmo salvífico en la figura del pueblo, que toma el manto de salvador. En contraste con la versión organicista, que diferencia las partes que integran el cuerpo colectivo (p. ej. catolicismo, fascismo), la interpretación izquierdista imbrica las utopías de democracia y comunismo, específicamente el autogobierno popular y el igualitarismo socioeconómico. Argumenta que el pueblo se organiza y lucha contra la élite opresora, que ilegítimamente gobierna, para establecer un nuevo y verdadero orden, marcado por la jefatura popular y la igualdad social (Mazzeo, 2014). En México esta utopía se condensa en la Revolución de 1910-1917 y adquiere continuidad con el 'nacionalismo revolucionario', ideología armada y pregonada por el régimen priista (1930-2000) para legitimarse (Pérez, 1999). El lopezobradorismo se nutre de este proceso utópico, conjugando el discurso populista de antagonismo pueblo-élite (Balderas y Tapia, 2019)² con un presunto posneoliberalismo que nivelaría la desigualdad social.

Como muestra el documental ¿Qué es La Calle?, sus integrantes han internalizado el discurso del poder popular, así: "todos los compañeros, sin excepción, todos son de lucha; son compañeros que lucharon por un cambio y siguen luchando por un cambio" (CLC, 2019b). La faceta religiosa de esta utopía se evidencia en formulaciones como "hay que luchar en contra de la corrupción y en contra de todo lo que esté en contra del pueblo" (CLC, 2019b), o "el movimiento tiene que avanzar... bajo una mística de lealtad a las luchas del pueblo; las exigencias del pueblo deben ser sagradas para la línea política de nuestro partido" (Villanueva, reunión 24 ago. 2019). Este aprendizaje ideológico se produce en el triángulo CLC-Morena-lopezobradorismo; por ejemplo, el Programa del partido, determinado por la visión de AMLO, articula la trama popular/populista de la que abreva el CLC (Morena, 2019, pp. 15-27). Ahora bien, en el Colectivo se despliegan mensajes contrapuestos. Por un lado, su líder enseña la teoría jacobina de la revolución permanente, que relativiza a personajes y organizaciones coyunturales: "la organización es permanente porque las necesidades son permanentes y mientras no haya justicia social cabal y no se pacifique el país"; "a nosotros como militantes no nos hacen los caudillos; no nos hizo Cuauhtémoc Cárdenas, menos Andrés Manuel; nos hace la calle... el andar reivindicando con dignidad, con valentía" (Villanueva, reunión 31 ago. 2019). Esta glorificación de la esencia popular contradice el culto a la personalidad de AMLO del lopezobradorismo, de nuevo posicionando al CLC como CMS. No obstante, pese a la retórica igualitaria, la dinámica del Colectivo pivota sobre el coordinador, quien, más que coordinar, dirige la publicación y las reuniones. El líder reconoce esta tensión entre idealismo y eficiencia organizacional: "sí hace falta quizá el tema de las comisiones para hacer más cosas, pero siempre me da miedo llegar a ese punto porque vamos a crear pequeñas burocracias que al final quien sabe si me sirvan, o si le sirvan al colectivo; soy yo muy patrimonialista" (G. Villanueva, comunicación personal, 11 de febrero de 2020). En todo caso, el grupo identifica el poder del pueblo con 'la izquierda', y ésta con los ideales revolucionarios clásicos -igualdad, libertad y fraternidad-, la democracia y los derechos humanos (CLC, 2019a, pp. 3 y 9). Además, la lucha popular entraña una comprensión neomarxista -sin que se emplee esta etiqueta-, que combina las doctrinas de colectivismo (CLC, 2019a, p. 10), lucha de clases - pueblo de izquierda versus élite de derecha/

2- No es objeto de este trabajo abordar el fenómeno populista. Aquí sólo cabe señalar que Balderas y Tapia, entre otros autores, conceptualizan el lopezobradorismo como populista; y que la literatura destaca como elemento central del populismo la generación y explotación del antagonismo pueblo-élite (p. ej. Mudde y Rovira, 2012). 
conservadora- y anticapitalismo: "el país, el planeta, lo está destruyendo un modelo de organización política que se llama capitalismo; y todavía la Cuarta Transformación no es un movimiento anticapitalista, pero dependerá de nosotros de que lo sea" (Villanueva, reunión 23 sep. 2019). Siguiendo el socialismo histórico, particularmente el cardenismo ${ }^{3}$, la anhelada emancipación pasa por "la conducción de un Estado fuerte que sea rector de la economía nacional[,] que sea respetado por su pueblo y por los gobiernos del mundo y sobre todo que vele por el bienestar y el interés general" (CLC, 2019a, p. 7).

Sobre este trasfondo épico de lucha popular contra el 'sistema', el CLC se erige como protagonista de su propia contienda, mostrando una dualidad identitaria semejante a la del partido-movimiento Morena. De una parte, se considera "red de movimientos" (CLC, 2019a, p. 3) del pueblo, a su servicio. Los participantes frecuentemente juegan con el nombre del grupo y su vocación popular: "[La Calle] trata de enseñar... lo que es exactamente eso, la calle" (CLC, 2019b). Constituye una vanguardia que lidera la lucha en varios frentes, concienciando y 'organizando' al pueblo, y si es preciso capitaneando la protesta social. De otra parte, el Colectivo promueve a Morena, vehículo político-institucional del MS amlista: "aquí el 99.9\% somos de Morena y el que no es lo será, porque lo vamos a convencer, precisamente porque... el que firma una credencial de afiliación es porque sabe que este país tiene que defenderse, no se puede entregar" (Villanueva, reunión 26 oct. 2019). Pero no es un apoyo incondicional, sino supeditado a una agenda izquierdista, porque ésta representaría la única ideología válida en la lucha popular y, concretamente, en el lopezobradorismo. A fin de cuentas, el oficialismo morenista siempre dice ser de izquierda. Así, el CLC se asume como izquierda de la izquierda y guardián del alineamiento del partido con el pueblo. Por ello es tan importante para este grupo asegurar que la presidencia de Morena esté bajo el control del ala izquierda del partido; $y$, a su parecer, solamente Luján posee una trayectoria ideológica intachable (Villanueva, 2019). Sin embargo, la partida de ajedrez entre candidatos finalmente ha favorecido al "ala moderada, por no decir de derecha, dentro de Morena, encabezada por Monreal [y Delgado, el aspirante]" (Villanueva, reunión 1 feb. 2020). A fines de febrero, Villanueva concluye, desanimado: "en verdad, toda esta lucha que dimos la militancia va a tener como cauce que se fortalezca este grupo [liderado por Delgado y Monreal]... [que] no es gente que ha nacido en la lucha" (reunión 29 feb. 2020). En aras de alcanzar el poder, el lopezobradorismo electoral dio cabida a distintas sensibilidades ideológicas (p. ej. coligándose con el conservador Partido Encuentro Social), hecho que el CLC reconoce y hasta agradece: "también gracias a ellos tenemos a Andrés Manuel como presidente” (Villanueva, reunión 31 ago. 2019). "Ellos”-la derecha lopezobradorista- han sido instrumento electoral del pueblo; y deben seguir siéndolo, pero ajustándose al marco izquierdista. Que no sea así -y no lo es- genera resentimiento en el Colectivo y refuerza su postura contramovilizadora, de resistencia política, respecto al 'nuevo' Morena.

Otra vertiente de CMS deriva de la alternancia política tras la elección de 2018, que ha dado paso al dominio de Morena sobre las instituciones públicas. De la mano de su líder, que ahora labora en el Senado, el CLC aprecia la política institucional para resolver los conflictos sociales. Se piensa como organización de la sociedad civil (CLC, 2019a, p. 10; CLC, 2019b), lo cual significa participar en la política institucional, ya sea aportando al desarrollo de políticas públicas o fiscalizando al Estado: "nos hemos convertido en una especie de unidad de gestión [de asuntos públicos]... tenemos todavía mucho por revisar entre nosotros, hasta dónde podemos tener este respaldo [institucional], ahora 3- Movimiento popular/-ista de Lázaro Cárdenas, presidente de México entre 1934 y 1940, quien nacionalizó el petróleo. AMLO ha reivindicado su figura. 
que tenemos aliados dentro del Gobierno" (Villanueva, reunión 7 dic. 2019). En esta capacidad, los integrantes del CLC critican la incompetencia de no pocos compañeros/as militantes, que gracias a su afiliación morenista han entrado a la administración pública. Muchos serían "oportunistas" ajenos a las luchas del pueblo, que no merecen ejercer el gobierno; metafóricamente: "los que no compartieron el taco placero ni la plomada entre albañiles vienen ahora a querer disfrutar de banquetes en sus grandes salones, con cargo al erario" (Sánchez, 2019, p. 3).

\subsection{Posneoliberalismo}

El posneoliberalismo da contenido a las formas heroica-salvífica y popular-de izquierda, aunque en la segunda ya se avista la tierra prometida del igualitarismo socioeconómico. Pero la utopía posneoliberal proporciona un relato más rico y ajustado a la actual coyuntura mexicana, lo cual aumenta su atractivo. Básicamente, el pueblo lucha contra el neoliberalismo, sistema económico injusto que genera desigualdad, instaurado por la élite político-económica, para establecer una economía justa que iguale la condición socioeconómica. El posneoliberalismo surge a raíz del MS trasnacional antineoliberal, que ha abanderado el eslogan 'otro mundo es posible' (Alguacil, 2003). El lopezobradorismo, como otros movimientos populares latinoamericanos (Fair, 2017, pp. 137-139), ha asumido esta utopía para articular su programa político-electoral, oponiéndose a los gobiernos neoliberales de las últimas tres décadas (Ackerman, 2019). Atendiendo al imaginario mexicano", desde (al menos) 2007 AMLO denomina esta utopía "Cuarta Transformación" (4T) (Salazar, 2007), pero el término sólo se afianza en el discurso público tras su victoria presidencial en 2018.

En el CLC no se discute qué es o debe ser la 4T; se (sobre)entiende que es el deseado cambio por el que el pueblo ha luchado y, por tanto, debe ser apoyado incondicionalmente. Con todo, el discurso colectivo deja entrever tres dimensiones de significación utópica: el escenario, los actores y los nudos de la trama. El escenario remite a la espacio-temporalidad de la 4T, en este caso México -dada la utopía nacionalista- y su historia. Ésta se divide en pre-historia y etapa neoliberal. Villanueva explica que desde tiempo inmemorial el clientelismo ha estructurado la política mexicana; aquí recurre a la autoridad del líder nacional: "cuando Andrés Manuel dice 'tenemos que evitar estos actos de clientela' es que la política mexicana desde el Porfiriato [1876-1911] y quizás antes pues era muy fácil ser líder si tenías qué regalar, con el dinero que no era tuyo, por supuesto; entonces eras el más popular" (reunión 31 ago. 2019). La violencia constituye un segundo rasgo de la pre-historia mexicana y continental, algo que la 4T ha evitado: "Andrés Manuel tenía que buscar una fórmula de transformación sin llegar a experimentar lo que se experimentó en los últimos 40 años de lucha revolucionaria, por lo menos, en América Latina. Es decir, no puedes tener una lucha [armada]" (G. Villanueva, comunicación personal, 11 de febrero de 2020). Clientelismo y violencia se sofistican bajo el régimen neoliberal. El primero ha absorbido a la sociedad civil, tejiendo una red de organizaciones que reciben dinero estatal a cambio de apoyo político (CLC, 2019a, pp. 10-11); y la violencia física se ha transmutado en "violencia económica, social, política y delincuencial... en los días de la globalización neoliberal” (Batres, 2020).

4- Los tres mitos fundacionales de la mexicanidad son la Independencia respecto a España (1810-1821), la Reforma liberal (1857-1861) en oposición al conservadurismo, y la Revolución mexicana (1910-1917) contra el régimen autoritario de Porfirio Díaz. Después de estas tres, la 4T se presenta como cuarta transformación. 
Siguiendo al lopezobradorismo, el CLC demoniza el neoliberalismo como fuente de todos los males de México: se trata de una conspiración e imposición de la élite - "la mafia del poder", según AMLOcontra el pueblo, que implica corrupción, produce desigualdad y exacerba los problemas sociales; en palabras de un articulista, "consiste en hacer una buena estrategia, para engañar, burlarse y manipular a los pueblos latinoamericanos, hasta prácticamente comprar a sus gobernantes y por medio de la privatización llegar al resultado de que el pobre es más pobre y el rico es más rico” (González, 2019). Precisamente, a la pregunta ¿cuál cree usted que sea el principal problema del país? los entrevistados responden que la corrupción y la desigualdad, herencias neoliberales (CLC, 2019b). No obstante, AMLO ganó y ha instaurado la 4T, que supuestamente pone remedio y fin al régimen neoliberal, el cual habría fracasado. La alternancia política y, sobre todo, el deseo utópico sesgan la interpretación de acontecimientos, que frecuentemente se entienden como 'pruebas' del descalabro neoliberal y, por tanto, de la nueva realidad posneoliberal: "es evidente que el coronavirus ha anticipado precipitadamente la caída del modelo neoliberal en todo el mundo, tal como lo afirmó en días recientes Andrés Manuel López Obrador" (Durán, 2020, p. 11).

El grupo delinea tres niveles de agencia actoral en la 4T: AMLO; el pueblo; y los GMS, concretamente Morena y el CLC. En primer lugar, la 4T es 'el proyecto del presidente', como indica este participante: "si no seguimos apoyando a Obrador, la Cuarta Transformación para nuestros hijos y para los demás no se va a dar; entonces hay que apoyar a Obrador más que nada” (reunión 24 ago. 2019). Esta identificación de la 4T con AMLO confirma el rasgo mesiánico del lopezobradorismo. Ahora bien, la 4T involucra al pueblo, que coopera con su caudillo: "debemos asumirla [la transformación] como una tarea colectiva, debemos trabajar en la reconstrucción del tejido social, el fortalecimiento de nuestra ciudadanía y de los lazos en comunidad, donde todas y todos trabajemos por el bien común" (Villarauz, 2019, p. 3). Este posneoliberalismo procura "el bien común", la justicia social, los derechos; en suma, converge con la utopía del poder popular de izquierda. Los GMS como Morena y el CLC facilitan esta labor comunitarista, pero de distintas maneras. Morena es la "herramienta" de AMLO para vehicular la 4T; en una reunión el coordinador recuerda a los asistentes que AMLO dijo que "existe Morena para que cuando yo no esté tengamos una herramienta eficaz de lucha, para transformar a este país, para que no regresemos otra vez a que los bandidos, canallas, estén al frente de las instituciones" (7 sep. 2019). En términos cristianos, Morena es la iglesia que el Mesías político lega a México. De otra parte, el CLC se concibe como baluarte del espíritu morenista -izquierda de la izquierda, infundida por el alma ideológica del pueblo o Espíritu Santo político-, lo cual en principio significa comulgar con Morena, pero en la práctica puede generar conflictos, como los santos con la iglesia: "somos un colectivo y trabajamos a favor de la comunidad, y vamos a seguir trabajando así, igual y si nos divorcian de Morena” (participante, reunión 29 feb. 2020). En esta línea, el entusiasmo por la 'buena nueva' posneoliberal conduce al proselitismo político: "tenemos que salir a la calle y encontrarnos con esa gente que quiere estar con nosotros, pero [todavía] no [lo] sabe... y de esa manera poder ayudar a Andrés Manuel, no darle más problemas" (Villanueva, reunión 1 feb. 2020).

Esta distinción de roles, institución versus intención, condiciona los nudos de la trama utópica. En relación con el heroísmo salvífico, el CLC critica a "oportunistas" como Monreal y Delgado que utilizan al partido, en lugar de sacrificarse por México. En cuanto al poder popular de izquierda, el grupo censura la desviación ideológica de Morena hacia la derecha, protagonizada por los mismos antihéroes. Respecto al posneoliberalismo, el Colectivo enfatiza su deseo de "cuidar" al partido, 
instrumento del pueblo que sobrevivirá el caudillaje de AMLO; quiere asegurar que no se descarrile de los rieles populares: "lo que nosotros tenemos que inyectarle al partido es esa mística de lucha, y de lucha permanente" (Villanueva, reunión 7 sep. 2019), "pues toda institución que se aleja del pueblo es como una planta que se seca por falta de agua y luz" (Sánchez, 2019, p. 4). La pugna por la presidencia de Morena ha puesto de relieve el peligro de regresión a 'viejas' prácticas partidarias; aludiendo a la elección interna el coordinador afirma que el "fraude no lo podemos permitir en Morena y no lo vamos a permitir... no vamos a dejar que se perredice Morena, que se haga priista Morena" (reunión 24 ago. 2019) 5 . En el mismo encuentro, para etiquetar esta determinación, Villanueva propone ser "tendencia", que es "la voz... exigente, firme, razonable que demande probidad y condena de expulsión al que mienta, robe o traicione... seamos una tendencia en la que defendamos los principios fundacionales de Morena". En respuesta, un asistente manifiesta: "tenemos que llegar a la calle a partir de hoy hasta las elecciones [internas]... para que realmente se viva... el espíritu de Morena con gente que tenga ese ADN de Morena y que no finja tener el ADN de Morena". Cuando unos meses después se anula el proceso electivo, el coordinador acusa a los opositores de Luján de promover "el acuerdo elitista, minoritario, no representativo y, sobre todo, no estatutario.... El acuerdo en lo oscurito, para decirlo en los términos del antiguo régimen" (reunión 11 dic. 2019). En fin, el fondo del posneoliberalismo consistiría en nuevas políticas públicas; y la forma, en una 'nueva política', con un partido realmente al servició del pueblo; a lo primero el CLC algo tiene que aportar, pero se cree especialmente legitimado y capaz para la segunda tarea. Además, el grupo estima que consolidar la 4T requiere más de un mandato presidencial, lo cual incentiva a seguir en el juego electoral y amortigua las decepciones en el camino utópico de la "transformación".

\section{Discusión}

El método del análisis narrativo del campo utópico aplicado al caso del CLC en relación con Morena verifica para el lopezobradorismo la hipótesis de discordia interna en movimientos que incluyen mediaciones utópicas instituyentes y proyectos partidarios que pretenden instituir las utopías mediadas. He mostrado cómo el CLC vehicula una contramovilización que se opone al lopezobradorismo pragmático, conservador y autocomplaciente que, según este grupo, se estaría instalando en Morena. Ello ilustra el choque de las lógicas utópica e instrumental, de fines y medios: el grupo enfatiza cómo se debe ejercer el poder; y el partido, que debe ejercerlo. Dicho esto, el discurso utópico del CLC coexiste con intereses y limitaciones individuales y colectivos, como reconoce su líder: "siempre va a haber problemas, por supuesto... de todos los niveles, de acuerdo a la formación de cada quien, desde los mezquinos hasta la falta de formación política, desde cuestiones de carácter personal" (G. Villanueva, comunicación personal, 11 de febrero de 2020). Así, las mediaciones utópicas aparentan mayor compromiso del que se practica; pero las apariencias igualmente inciden en la construcción social de la realidad.

El surgimiento del CLC como CMS dialéctico radica en el éxito electoral de Morena, logro que -predicado sobre la inclusión política bajo el caudillaje de AMLO- integra tres contradicciones: (i) la cadu- 
cidad de AMLO como líder político (iniciada con su renuncia a presidir Morena en 2017 y completada cuando termine su mandato presidencial en 2024), que cuestiona la identidad del MS; (ii) la diversidad ideológica de los seguidores amlistas, que no necesariamente creen en una agenda de izquierda (algo en todo caso ambiguo) ni en la preeminencia de la lógica popular/populista; y (iii) la entrada de Morena al aparato político-institucional, acomodo que supone la asunción de prácticas políticas tradicionales, acaso ajenas al ideario emancipador. Por otro lado, Meyer y Staggenborg (1996, pp. 1635-1643) indican tres factores favorables a la creación de un CMS: éxito del MS, amenaza de sus objetivos para algún grupo, y aliados políticos. Estas condiciones aplican al CLC: primero, el lopezobradorismo ha alcanzado y domina el poder político-institucional a través de Morena; segundo, el pragmatismo morenista contraviene utopías que vertebran al lopezobradorismo; y, tercero, algunos dirigentes de Morena (Luján, Batres) buscan contrarrestar esta "burocratización" partidaria, por ejemplo, apoyando al CLC.

La Figura 1 delinea la relación del MS lopezobradorista consigo mismo, cuando su GMS dominante, Morena, se desplaza afuera del marco utópico que un GMS no dominante, el CLC, establece para el MS. En general (Figura 2), cualquier GMS dominante (GMSd) está sujeto a la fiscalización de GMS no dominantes (GMSnd), los cuales pueden erigirse en CMS si perciben desviaciones 'intolerables', como por ejemplo una traición a las utopías que articulan el MS. En ese caso, la contramovilización de GMSnd agraviados, aquí del CLC, procura eliminar políticamente al sector transgresor.

Figura 1

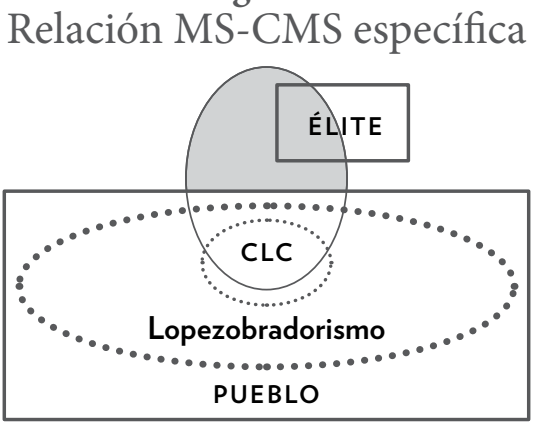

Elaboración propia / Enfrentamiento entre el CLC y el sector (marcado en gris) de Morena que, a decir del CLC, no está alineado con el lopezobradorismo.

Figura 2
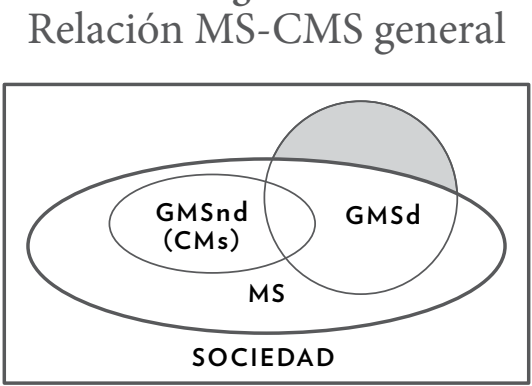

Elaboración propia / Enfrentamiento entre un (o varios) GMS no dominante (GMSnd) y el sector (marcado en gris) del GMS dominante (GMSd) que, a decir del primero, no está alineado con el MS. 
Esta dinámica ha sido identificada en el estudio de MS y partidos políticos. En su investigación sobre el feminismo estadounidense entre 1966 y 1975 Barbara Ryan (1989) señala una animosidad entre pequeños grupos feministas, que se piensan radicales, y la Organización Nacional por las Mujeres (NOW), a la que acusan de conservadurismo. La autora concibe este posicionamiento contramovilizador como purismo ideológico, acentuando así su dimensión simbólica. Por su parte, Michael Murakami (2008) denomina grupos de pureza partidaria a aquellas organizaciones que presionan a los partidos republicano y demócrata en Estados Unidos a mantener sus líneas ideológicas tradicionales. Si la contramovilización al feminismo liberal de NOW contribuyó a la desarticulación del MS, estos lobbies ideológicos son capaces de movilizar cantidad de recursos para sus propósitos y, por tanto, producen el resultado opuesto, es decir, el mantenimiento de una identidad política diferenciada. Entre estos extremos, el CLC no puede incidir en el lopezobradorismo ni en Morena de forma determinante, al menos de momento. A futuro, si el partido diluye su dimensión utópica y abraza el pragmatismo electoralista, el grupo puede optar por desvincularse del partido, ajustar a la baja sus expectativas utópicas, o mantener su purismo, afianzando una identidad de resistencia, atrincheramiento y victimismo.

La pugna entre el CLC y Morena refleja una dinámica amplia de institucionalización utópica limitada o fallida, según se entienda, que ha sido observada en el desarrollo de la 'marea rosa' en América Latina. Las utopías del poder popular y del posneoliberalismo que motivan los MS populares/populistas han enfrentado las estructuras preexistentes y simbióticas de la democracia liberal y el capitalismo neoliberal y, en la negociación partidaria y gubernamental, se han logrado algunos avances en la reducción de la desigualdad y el incremento de la participación social y política a cambio de la aceptación y continuidad de la hegemonía (neo)liberal (Munck, 2015, p. 379; Emerson, 2018, p. 174; Soler, 2020). Este acomodo, que ha sido conceptualizado como neodesarrollismo (Katz, 2016), implica cierta estatización de la economía, particularmente de los recursos naturales, con el propósito de redirigir la plusvalía a sectores sociales tradicionalmente desfavorecidos; así, se incrementa la inclusión socioeconómica y, desde luego, el apoyo político-electoral (Carcanholo, 2019). Sin embargo, al dejar intacta la matriz (neo)liberal, estas mejoras han resultado precarias, sujetas -valga el juego de palabras- a mareas políticas y, por ello, actualmente en retroceso. Cabe preguntarse, por tanto, qué tanto este tipo de izquierda puede romper con el paradigma de derecha o si, más bien, le es funcional como alternativa simulada, es decir, otro instrumento de dominación para cooptar y regular el descontento social (de Nieves, 2015, p. 28). Según Frei Betto (Martínez, 2016), "esos gobiernos [democrático-populares] ... han cometido dos grandes errores: no han tratado de organizar y politizar al pueblo"; esta valoración refleja el alejamiento entre el partido, de orientación institucional-estatal, y su base social, de inspiración utópica (Zibechi, 2016, p. 27; Fair, 2017, p. 142). Quizá lo que está faltando es una utopía pospartidista, que rechace la dominación de los partidos sobre el proceso político institucional y abra el significado y las prácticas de institucionalización utópica.

\section{Conclusión}

El desencanto con la política institucional favorece el desarrollo de MS de corte utópico, que motivan la movilización política. En la reciente ola de izquierdismo gubernamental en América Latina se ha experimentado con la institucionalización de la utopía posneoliberal, con resultados mixtos o 
incluso desfavorables, atendiendo a la continuidad del modelo neoliberal. En México la 4T igualmente promete una "transformación" paradigmática, vehiculada por el MS lopezobradorista y su herramienta partidaria, Morena. A través de la propuesta metodológica del análisis narrativo del campo utópico, este trabajo ha abordado el caso del CLC, grupo lopezobradorista que se contramoviliza ante la "burocratización" de Morena. El análisis de tres mediaciones utópicas de este colectivo -heroísmo salvífico, poder popular de izquierda y posneoliberalismo- apoya la hipótesis teórico-empírica de tensión entre grupos utópicos instituyentes y los partidos supuestamente encargados de instituir tales utopías. El control ideológico que los primeros pretenden ejercer sobre los segundos topa con la necesidad pragmática de acomodar ideales a la hegemonía preexistente, y en esa negociación lo utópico se diluye. Si esto sucede en el marco de la hegemonía de los partidos sobre el proceso político institucional, cabe plantear el interrogante de qué ocurriría si se introduce una utopía pospartidista. En todo caso, a futuro es preciso ahondar en la heterogeneidad del lopezobradorismo en relación con la implantación de la $4 \mathrm{~T}$ y qué consecuencias se desprenden para la democracia mexicana.

\section{Referencias}

Ackerman, J. M. (2019). Introducción. En J. M. Ackerman (coord.), El cambio democrático en México: retos y posibilidades de la "Cuarta Transformación" (pp. 23-60). Siglo XXI.

Alexander, J. C. (2009). Hacerse héroe en la batalla democrática por el poder. Revista Mexicana de Ciencias Políticas y Sociales, 51(207), 105-115. http://dx.doi.org/10.22201/ fcpys.2448492xe.2009.207.41018

Alguacil Gómez, J. (2003). La utopía de los nuevos movimientos sociales en marcha: "otro mundo es posible”. Sociedad y Utopía, 22, 135-153. http://www.sociedadyutopia.es/index.php/revistas-publicadas

Balderas Zavala, R. G. y Tapia Ornelas, M. (2019). Algunos de los rasgos populistas de AMLO. El Cotidiano, 213, 28-36. http://www.elcotidianoenlinea.com.mx/

Batres, M. (2020, marzo). G. Villanueva Albarrán (ed.). Machismo y neoliberalismo. La Calle, 43, 12. Berthelot, J-M. (1998). L 'inteligence du social. Le pluralisme explicatif en sociologue. PUF.

Bolívar Meza, R. (2017). Movimiento de Regeneración Nacional: democracia interna y tendencias oligárquicas. Foro Internacional. 57(2), 460-489. https://doi.org/10.24201/fi.v57i2.2385

Bolívar Meza, R. (2014). Morena: el partido del lopezobradorismo. Polis, 10(2), 71-103. https://polismexico.izt.uam.mx/index.php/rp/article/view/239

Calvo, K. y Álvarez, I. (2015). Limitaciones y exclusiones en la institucionalización de la indignación: del 15-M a Podemos. Revista Española de Sociología, 24, 115-122. https://recyt.fecyt.es/index. $\mathrm{php} / \mathrm{res} /$ article/view/65426

Carcanholo, M. (2019). Neoliberalismo y dependencia contemporánea: alternativas de desarrollo en América Latina. En P. Vidal Molina (coord.), Neoliberalismo, neodesarrollismo y socialismo bolivariano. Modelos de desarrollo y políticas públicas en América Latina (pp. 34-50). Ariadna.

Carretero Pasin, E. (2008). Religiosidades instituyentes/Religiones instituidas. Nómadas, 18(2). http:// www.theoria.eu/nomadas/18/index.html 
Castellanos Obregón, J. M. (2013). El diseño metodológico y los esquemas de inteligibilidad. Red Latinoamericana de Metodología de las Ciencias Sociales, 3(1). https://www.relmecs.fahce.unlp.edu. ar/article/view/RELMECSv03n01a01

Colectivo La Calle. (2019a, febrero). G. Villanueva Albarrán (ed.). ¿Qué es la Calle? La Calle, número especial.

Colectivo La Calle. (2019b). ¿Qué es La Calle? Tercer aniversario del Colectivo La Calle [Documental]. https://www.youtube.com/watch?v=DHlq2BACZ_8

Compte Nunes, G. (2020). Construyendo una utopía pospartidista en el México contemporáneo: marcos utópicos de dos grupos contestatarios críticos de la democracia existente. INTERdisciplina, 8(22), 39-65. http://dx.doi.org/10.22201/ceiich.24485705e.2020.22.76417

Dader, J. L. (2015). Fascinados por "Podemos". Un fenómeno natural de la "Democracia Sentimental”. H-ermes. Journal of Communication, (4), 13-45. https://dx.doi.org/10.1285/i22840753n4p13

de Nieves, A. (2015). ¿Asalto a las instituciones? Algunos apuntes sobre la relación entre Podemos y el movimiento del 15 de mayo. En E. Mateo Regueiro (dir.), Hasta luego, Pablo: once ensayos críticos sobre Podemos (pp. 21-28). Los libros de la catarata.

Díaz Parra, I., Jover Báez, J. y Roca Martínez, B. (2017). Del 15M al giro electoralista. Proyectos espaciales y fetiches políticos en las estrategias de acción colectiva. Cuadernos Geográficos, 56(1), 344-364. https://revistaseug.ugr.es/index.php/cuadgeo/article/view/4692

Dorf, M. C. y Tarrow, S. (2014). Strange bedfellows: how an anticipatory countermovement brought same-sex marriage into the public arena. Law y Social Inquiry, 39(2), 449-473. https://doi. org/10.1111/lsi.12069

Durán, S. (2020, abril). G. Villanueva Albarrán (ed.). Fracaso neoliberal ante el Covid-19. La Calle, 44, 10-11.

Emerson, R. G. (2018). La "marea rosa” en América Latina: orígenes y posibles trayectorias. En J. C. Gachúz Maya, C. Barona Castañeda y G. Rodríguez Sánchez Lara (coords.). Escenarios regionales contemporáneos: retrato de un mundo globalizado (pp. 153-178). Fundación Universidad de la Américas Puebla.

Emirbayer, M. (1997). Manifesto for a Relational Sociology. The American Journal of Sociology, 103(2), 281-317. https://doi.org/10.1086/231209

Estrada Saavedra, M. (2015). Sistemas de protesta. El Colegio de México.

Fair, H. (2017). Reflexiones sobre los gobiernos de centroizquierda latinoamericana y sus limitaciones políticas en los albores del mundo del siglo XXI. En R. Salazar Pérez y M. Heinrich (coords.), El rostro difuminado de la sociedad 2020 en América Latina (pp. 129-186). Elaleph.

Feixa, C., Perondi, M. y Castro, G. (2015). O peregrino indignado: topías e utopias do 15M. Tomo, 27, 397-428. https://doi.org/10.21669/tomo.v0i0.4656

Flesher Fominaya, C. (2007). Autonomous movements and the institutional Left: two approaches in tension in Madrid's Anti-globalization Network, South. European Society y Politics, 12(3), 335358. https://dx.doi.org/10.1080/13608740701495202

González, A. (2019, noviembre). G. Villanueva Albarrán (ed.). ¿El fin del Neoliberalismo en América Latina? La Calle, 38, 9. 
Heraldo de México. (2020, 1 de abril). Mario Delgado, favorito para dirigir Morena, revela encuesta. Heraldo de México. https://heraldodemexico.com.mx/nacional/2020/4/1/mario-delgado-favorito-para-dirigir-morena-revela-encuesta-164492.html

Infobae. (2019, 29 de agosto). Monreal vs. Batres: el conflicto por la Mesa Directiva de Morena en el Senado. Infobae. https://www.infobae.com/america/mexico/2019/08/29/monreal-vs-batres-elconflicto-por-la-mesa-directiva-de-morena-en-el-senado/

Katz, C. (2016). Neoliberalismo, neodesarrollismo, socialismo. Batalla de ideas.

Levitas, R. (2010). The concept of utopia. Peter Lang.

Mannheim, K. (2004). Ideología y utopía. FCE.

Martín, I. (2015). Podemos y otros modelos de partido-movimiento. Revista Española de Sociología, 24, 107-114. https://recyt.fecyt.es/index.php/res/article/view/65425

Martínez, N. (2016, 6 de diciembre). Frei Betto: Los errores de la izquierda son no organizar ni politizar al pueblo. Resumen Latinoamericano. https://www.resumenlatinoamericano.org/2016/12/07/ frei-betto-los-errores-de-la-izquierda-son-no-organizar-ni-politizar-al-pueblo/

Martínez, R. (2019, noviembre). G. Villanueva Albarrán (ed.). Puntos estratégicos del proyecto de la Nueva República. La Calle, 38, 5-6.

Mazzeo, M. (2014). Introducción al poder popular (2. ${ }^{\mathrm{a}}$ ed.). Tiempo robado.

McCarthy, J. D. y Zald, M. N. (1977). Resource mobilization and social movements: a partial theory. American Journal of Sociology, 82(6), 1212-1241. https://doi.org/10.1086/226464

Melucci, A. (1991). La acción colectiva como construcción social. Estudios Sociológicos, 9(26), 357364. https://estudiossociologicos.colmex.mx/index.php/es/article/view/911

Meyer, D. S. y Staggenborg, S. (1996). Movements, countermovements, and the structure of political opportunity. American Journal of Sociology, 101(6), 1628-1660. https://doi.org/10.1086/230869

Morena (2019). Documentos básicos. JyM Adhesive Labels.

Mudde, C. y Rovira Kaltwasser, C. (2012). Populism and (liberal) democracy: a framework for analysis. En C. Mudde y C. Rovira Kaltwasser (eds.), Populism in Europe and the Americas: threat or corrective for democracy? Cambridge University Press.

Munck, G. L. (2015). Building democracy... Which democracy? Ideology and models of democracy in post-transition Latin America. Government and Opposition, 50(3), 364-393. https://dx.doi. org/10.1017/gov.2015.2

Murakami, M. H. (2008). Divisive primaries: Party organizations, ideological groups, and the battle over party purity. Political Science and Politics, 41(4), 918-923. https://doi.org/10.1017/ S104909650838127X

Pérez Montfort, R. (1999). Un nacionalismo sin nación aparente. (La fabricación de lo "típico" mexicano 1920-1950). Política y Cultura, (12), 177-193. https://polcul.xoc.uam.mx/index.php/polcul/ article/view/231

Pinho de Oliveira, M. F. (2020). ¿Sacralización política o mesianismo? Los liderazgos políticos de Néstor Kirchner, Hugo Chávez, Donald Trump y Jair Bolsonaro. Tla-Melaua, 13(47), 322-342. http://www.apps.buap.mx/ojs3/index.php/tlamelaua/article/view/866

Polletta, F., Chen, P. C. B., Gardner, B. G. y Motes, A. (2011). The sociology of storytelling. Annual Review of Sociology, 37, 109-130. https://doi.org/10.1146/annurev-soc-081309-150106 
Ryan, B. (1989). Ideological purity and feminism: The U.S. Women's Movement from 1966 to 1975. Gender y Society, 3(2), 239-257. https://doi.org/10.1177/089124389003002005

Salazar, C. (2007, 6 de mayo). Descarta AMLO rupturas. Reforma. https://reforma.vlex.com. $\mathrm{mx} / \mathrm{vid} /$ descarta-amlo-rupturas-196247891?_ga=2.95247708.1338894562.1611009165968799262.1611009165

Sánchez, J. F. (2019, noviembre). G. Villanueva Albarrán (ed.). Entre el PRI y el PRD, ¿no hay de otra sopa para MORENA? La Calle, 38, 3-4.

Sandoval, I. (2020, enero). G. Villanueva Albarrán (ed.). Los valores a reestructurar en la 4T. La Calle, $41,6-7$.

Soler, L. (2020). Populismo del siglo XXI en América Latina. Estado y comunes, 10(1), 17-36. https:// doi.org/10.37228/estado_comunes.v1.n10.2020.146

Villanueva, G. (2019, noviembre). G. Villanueva Albarrán (ed.). Editorial. La Calle, 38, 2.

Villarauz, R. (2019, diciembre). G. Villanueva Albarrán (ed.). Morena y el camino para recuperar nuestra ciudad como capital segura y libre de violencia para las mujeres. La Calle, 39, 2-3.

Zald, M. N. (1979). Macro issues in the theory of social movements: SMO interaction, the role of counter-movements and cross-national determinants of the social movement sector. CRSO Working Paper, 204. https://deepblue.lib.umich.edu/handle/2027.42/50978

Zibechi, R. (2016). Progressive Fatigue? NACLA Report on the Americas, 48(1), 22-27. https://dx.doi. org/10.1080/10714839.2016.1170298 